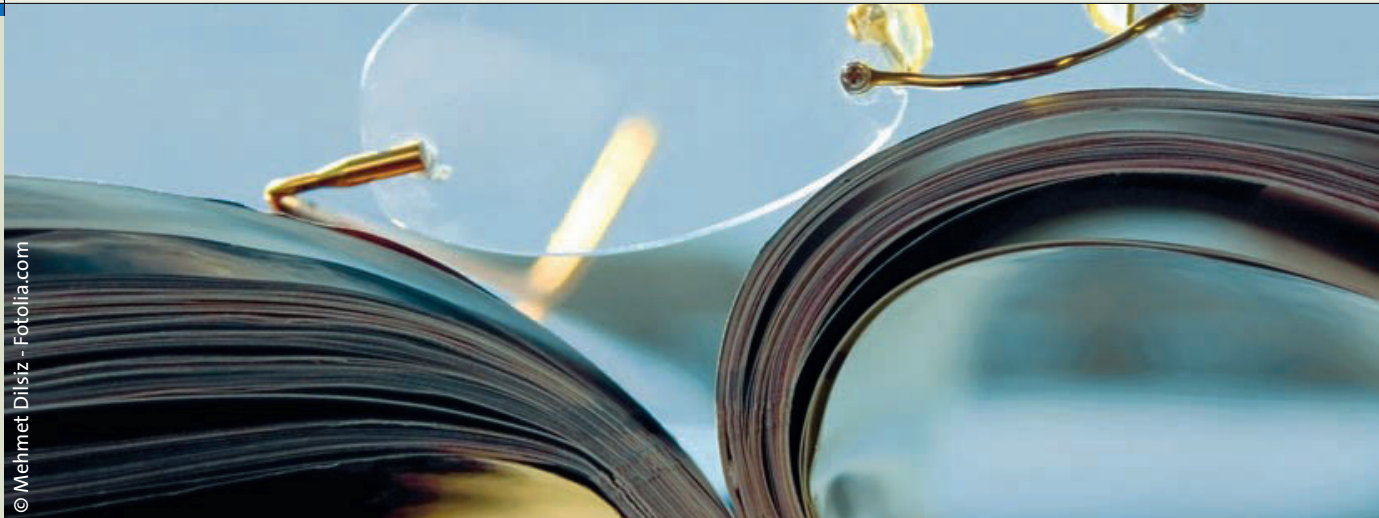

\title{
Hand rot-weiß
}

Ein 14-jähriges Mädchen wurde zur Abklärung von intermittierenden Episoden akuter Schmerzen in Händen und Füßen vorgestellt.

A uslöser für die Beschwerden waren in den meisten Fällen körperliche Aktivität und/oder Aufenthalt im Wasser. Während der körperlichen Untersuchung ließ sich durch eine repetitive Bewegung der rechten Hand ein brennender Schmerz und eine akute Rötung auslösen (s. Abb.). Ein ähnliches Phänomen trat bei Erwärmung der Hand in warmem Wasser auf.

Symptomatik und Auslöser sind typisch für die Erythromelalgie, bei der es durch eine Erhöhung der Hauttemperatur zu schmerzhaften Attacken und Rotverfärbungen sowie Schwellungen an Händen und Füßen kommt. Abküh- lung der betroffenen Extremität führt regelhaft zu einem Rückgang der Symptomatik. Der Symptomenkomplex ist assoziiert mit myeloproliferativen Erkrankungen, Kollagenosen, Vaskulitiden, Diabetes, Gicht und einer Reihe von Medikamenten. Während die Symptome bei myeloproliferativen Erkrankungen üblicherweise gut auf Aspirin ansprechen, ist die Therapie bei anderweitigen Grunderkrankungen schwierig.

Fazit: Selbst wenn die Behandlung wenig erfolgreich ist, so ist vielen Patienten doch damit gedient, wenn der behandelnde Arzt eine sichere Diagnose aufgrund der Ana-

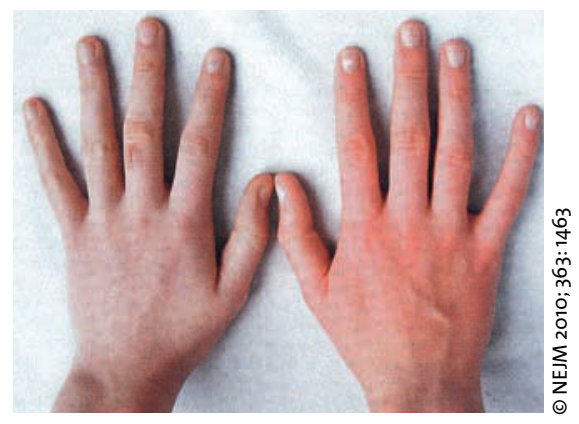

Rötung der rechten Hand nach Bewegung.

mnese und des klinischen Befundes stellt, den Patienten über die relative Harmlosigkeit aufklärt und Verhaltensmaßregeln an die Hand gibt.

H. S. FüeßI

Lipsker D. A white hand and a red hand erythromelalgia. New Engl J Med 2010; 363: 1463

DR6 deutlich seltener in der Patientenkohorte vertreten - offenbar ein protektiver Faktor. HLA-DR6-positive Individuen scheinen diesen Daten zufolge ein siebenfach geringeres Risiko zu haben, dass sich auf ihrer Haut Warzen entwickeln.

Fazit: Auch wenn die Autoren auf eine HPV-Typisierung verzichteten und die Ergebnisse in Teilen im Widerspruch zu der genannten älteren Studie stehen: Die Bedeutung des HLA-Systems für den Verlauf von HPV-Infektionen der Haut wird durch die Befunde unterstrichen.

Garcia-Corona C et al. HLA-DR-alleles associated with skin warts induced by human papillomavirus infection. Int J Dermatol. 2010; 49:1376-9 